\title{
RBS/Channeling Analysis of Zinc Oxide Films Grown at Low Temperature by Atomic Layer Deposition
}

\author{
R. Ratajczak ${ }^{a}$, A. Stonert ${ }^{a, *}$, E. Guziewicz ${ }^{b}$, S. Gieraltowska ${ }^{b}$, T.A. Krajewski ${ }^{b}$ \\ G. LUKA $^{b}$, L. WACHNICKI ${ }^{b}$, B.S. WitKOWSKI ${ }^{b}$ AND M. GODLEWSKI ${ }^{b}$ \\ ${ }^{a}$ National Centre for Nuclear Research, Hoża 69, 00-681 Warsaw, Poland \\ ${ }^{b}$ Institute of Physics, Polish Academy of Sciences, al. Lotników 32/46, 02-668, Warsaw, Poland
}

\begin{abstract}
The results of the Rutherford backscattering/channeling study of ZnO layers are presented. ZnO layers were deposited on the silicon single crystals and GaN epitaxial layers at low temperature by atomic layer deposition. Deposition temperature varied between 100 and $300{ }^{\circ} \mathrm{C}$. A random spectra analysis was performed to determine layer thickness and composition. In turn, analysis of the aligned spectra allows us to study evolution of ingrown defects. The Rutherford backscattering study supports the results of X-ray photoelectron spectroscopy measurements, performed separately, that the ZnO-ALD layers deposited at low temperature contain a higher oxygen content. Composition measurements, performed as a function of growth temperature, show that oxygen content decreases with the increasing temperature of the atomic layer deposition growth process.
\end{abstract}

DOI: $10.12693 /$ APhysPolA.123.899

PACS: 77.55.hf, 81.05.Dz, 81.15.Hi, 68.55.ag, 82.80.Yc, 61.85.+p

\section{Introduction}

During the last few years we have demonstrated that $\mathrm{ZnO}$ is an attractive material for several new applications in electronics (cross-bar memories [1], transparent electronics [2]), photovoltaic [3] and optoelectronic devices, such as light-emitting diodes (LEDs), optically pumped lasers, and transparent thin films transistors [3-5]. It is a transparent semiconductor compound with a direct wide band gap (3.37 eV at room temperature, RT), large excitonic binding energy $(60 \mathrm{meV})$, insensitive to visible light and amenable to wet etching and resistant to radiation damage.

A direct band-gap and the related transparency make some of the above mentioned applications of zinc oxide possible [2-4]. In many features $\mathrm{ZnO}$ is similar to $\mathrm{GaN}$, but the production of $\mathrm{GaN}$ is much more difficult and expensive than that of $\mathrm{ZnO}$, so zinc oxide became a good alternative to gallium nitride for optoelectronic applications. Unfortunately, problems with the $p$-type properties of $\mathrm{ZnO}$ have not been solved yet. This limits applications of $\mathrm{ZnO}$ in light emitting devices. Thus, control of electrical properties of $\mathrm{ZnO}$ is crucial. In the present work we address this problem by investigating the stoichiometry of $\mathrm{ZnO}$ layers grown at low temperature (important for some of applications $[1-4,6]$ ) by atomic layer deposition (ALD).

Zinc oxide of wurtzite structure can be produced as a bulk crystal by several growth methods, including a hydrothermal one. In turn, thin films of $\mathrm{ZnO}$ (amorphous, polycrystalline or monocrystalline) can be deposited by a range of techniques, including sputtering, molecular

\footnotetext{
*corresponding author; e-mail: stona@fuw.edu.pl
}

beam epitaxy (MBE), metalorganic chemical vapor deposition (MOCVD), pulse laser deposition (PLD) and atomic layer deposition $[1-4,6]$. In the present work we investigate the properties of $\mathrm{ZnO}$ films grown by ALD. This method enables very uniform layers with large surfaces, excellent precision of thickness control, and a low growth temperature to be obtained [7].

The latter property of ALD (low growth temperature) is important for several applications. For example, for production of $\mathrm{ZnO}$ /organic material hybrid structures $[8,9]$. Thus, ALD-grown $\mathrm{ZnO}$ films deposited in the low temperature regime (below $300^{\circ} \mathrm{C}$ ) have been intensively investigated recently because of their great potential for such novel electronic applications as switch elements in three-dimensional memories [1] and inorganic partners of hybrid organic-inorganic structures $[8,9]$.

Control of defects and related conductivity in the $\mathrm{ZnO}$ layers grown at low temperature by ALD still remains a challenge as it is significantly different from the $\mathrm{ZnO}$ films grown at higher temperatures $[2-4,6]$. Zinc interstitials and oxygen vacancies are among the main native defects in the $\mathrm{ZnO}$ crystals and films [10], therefore the stoichiometry control of this material is of great importance as it influences its electrical characteristics.

In the present work we employed the Rutherford backscattering (RBS)/channeling technique [11] for evaluation of the properties of $\mathrm{ZnO}$ layers. $\mathrm{RBS}$ is a nondestructive technique which is used for quantitative depth profiling and thickness measurements, especially for thin films [12] and multilayers [13, 14]. The energy loss of the ions gives depth information. The film thickness can be calculated provided the material density is known. Since the spectrum intensity is proportional to the local content of an element, the shape of the energy spectrum reflects its depth profile. In the case of the crystalline layers it is possible to detect interstitials and other kinds of lattice disorder with the ion-channeling technique. 


\section{Experimental}

Thin layers of $\mathrm{ZnO}$ were deposited by ALD using a Savannah 100 ALD system from Cambridge Nanotech. Diethylzinc (DEZn, $\left.\mathrm{Zn}\left(\mathrm{C}_{2} \mathrm{H}_{5}\right)_{2}\right)$ and deionized water were used as organic zinc and oxygen precursors. We used high purity $\mathrm{N}_{2}$ as a purging gas. A series of polycrystalline zinc oxide films deposited on silicon ( $\mathrm{Si}\langle 001\rangle$ substrates) by ALD at different temperatures, and crystalline layers on $\langle 0001\rangle \mathrm{GaN} / \mathrm{Al}_{2} \mathrm{O}_{3}$ templates were analyzed.

Film thickness, stoichiometry and crystallinity were determined from the RBS/channeling investigations (see Ref. [11] for a description of the method). Experiments were carried out using a $1.7 \mathrm{MeV}{ }^{4} \mathrm{He}^{+}$ion beam from the Van de Graaff accelerator at the Helmholtz Zentrum Dresden-Rossendorf (HZDR), Germany. Backscattered particles were detected at $160^{\circ}$ with respect to the beam direction, and the beam was collimated to a diameter of $1.25 \mathrm{~mm}$. Energy resolution and full width at half maximum (FWHM) of the detection system was $18 \mathrm{keV}$. All spectra were collected with the charge $40 \mu \mathrm{C}$ and as rotating randomly in order to avoid channelling effect. During rotation of the sample an angular scan was recorded to detect if the layer was crystalline. If the result was positive, the channelling spectrum was also measured. The SIMNRA backscattering spectra simulation code [15] was applied for random spectra analysis.

Scanning electron microscopy (SEM) investigations were performed with a Hitachi SU-70 microscope. SEM spectra were taken at relatively low accelerating voltages either at RT or at $5 \mathrm{~K}$. Surface morphology was investigated by an atomic force microscope (AFM).

Electrical parameters were also investigated. The Hall measurements were performed in the van der Pauw geometry using the RH2035 PhysTech GmbH system equipped with a permanent magnet producing the magnetic field $B=0.426 \mathrm{~T}$. The e-beam evaporated bi-layers of $\operatorname{Ti}(100 \AA) / \mathrm{Au}(400 \AA)$ were used as ohmic contacts to $\mathrm{ZnO}$.

\section{Results}

\subsection{Composition analysis of $\mathrm{ZnO}$ layers on $\mathrm{Si}$}

Figure 1 shows the typical RBS random spectra of $\mathrm{ZnO}$ deposited on Si by the ALD method at different growth temperatures. The large peak on the right-hand side is due to the zinc atoms whereas the oxygen signal appears on the Si background. To avoid overlapping of spectra we examined layers with slightly different thicknesses.

RBS is not equally sensitive to various elements. The height of the RBS signal depends on the scattering cross-section which is proportional to the square of the atomic number of the element. Thus, for light elements the RBS signal is much lower than for heavy ones [11]. Therefore, it is quite difficult to separate the signal from such elements as nitrogen, carbon or oxygen, from the high background of much heavier substrates. Consequently, it is quite difficult to evaluate the contribution of light

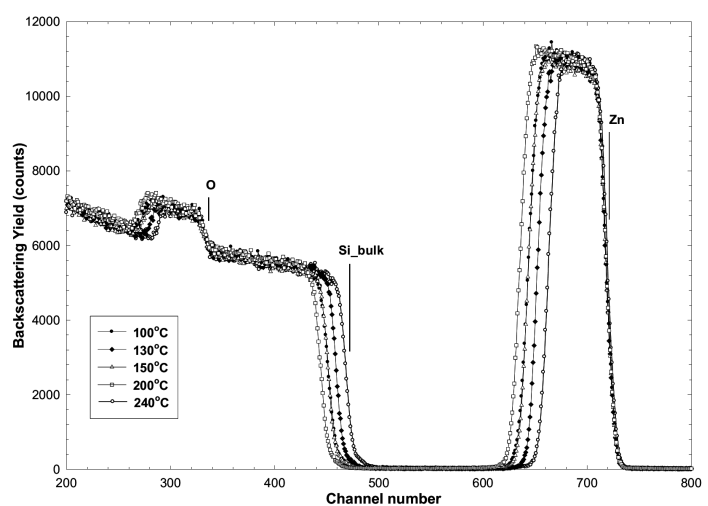

Fig. 1. RBS random spectra for the $\mathrm{ZnO}$ layers deposited on $\mathrm{Si}$ by the ALD technique at different temperatures.

elements. Moreover, the results obtained strongly depend on the background cut off method. To avoid such ambiguous results the SIMNRA simulations were performed. The layer thicknesses obtained from these simulations vary from 110 to $180 \mathrm{~nm}$, depending on the number of ALD cycles and the growth temperature. Figure $2 \mathrm{a}$ shows some differences in the slopes of the $\mathrm{Zn}$ low energy edge from the theoretical ones (predicted for the experimental FWHM). This led us to the conclusion that sample surface roughness could be responsible for this effect. Sample surface roughness was estimated to be about $10 \mathrm{~nm}$. The presence of roughness of this range was confirmed by independent AFM measurements, as shown in Fig. 2b.

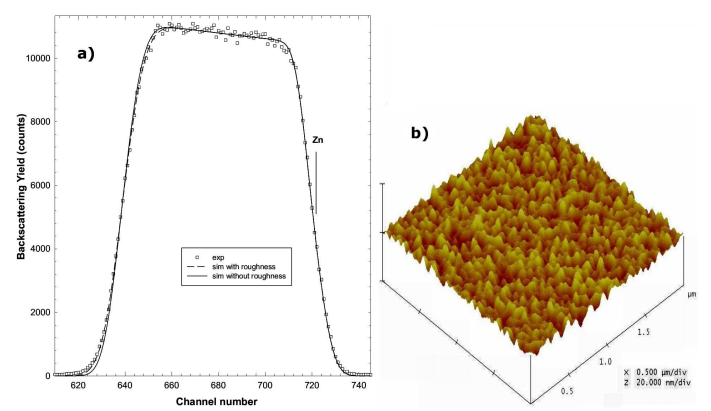

Fig. 2. Roughness analysis for the $\mathrm{ZnO}$ layer deposited on $\mathrm{Si}$ at $200^{\circ} \mathrm{C}$ : (a) Zn signal from the RBS random spectrum, (b) the AFM image.

Zinc content in the $\mathrm{ZnO}$ layers was also evaluated from the RBS random spectra. It has been found that the O:Zn content exceeds 1 for each of growth temperatures. Figure 3 shows the dependence of the O:Zn ratio on the deposition temperature. As can be seen, oxygen content decreases with the increasing growth temperature. The results are summarized in Table. Importantly, the stoichiometry of the ALD layers reveals no influence of the substrate used ( $\mathrm{Si}$ or GaN/sapphire template). 
TABLE

Layer thicknesses and $\mathrm{O}: \mathrm{Zn}$ ratio for the $\mathrm{ZnO}$ films determined by the RBS and electrical properties determined by the Hall measurements.

\begin{tabular}{c|c|c|c|c|c}
\hline \hline Sample & $\begin{array}{c}\text { Growth } \\
\text { temperature } \\
{\left[{ }^{\circ} \mathrm{C}\right]}\end{array}$ & $\begin{array}{c}\text { Thickness } \\
{[\mathrm{nm}]}\end{array}$ & $\begin{array}{c}\text { O:Zn } \\
\text { ratio }\end{array}$ & $\begin{array}{c}\text { Carrier } \\
\text { concentration } n \\
{\left[\mathrm{~cm}^{-3}\right]}\end{array}$ & $\begin{array}{c}\text { Mobility } \\
{\left[\mathrm{cm}^{2} /(\mathrm{Vs})\right]}\end{array}$ \\
\hline $\mathrm{S} 635$ & 100 & 162 & $1.08(7)$ & $1.7 \times 10^{17}$ & 3 \\
S705 & 130 & 178 & $1.07(6)$ & $2.0 \times 10^{19}$ & 20 \\
S703 & 160 & 165 & $1.07(1)$ & $3.6 \times 10^{19}$ & 22 \\
S701 & 200 & 136 & $1.06(8)$ & $8.6 \times 10^{19}$ & 26 \\
S180a & 240 & 111 & $1.06(6)$ & $1.1 \times 10^{20}$ & 21
\end{tabular}

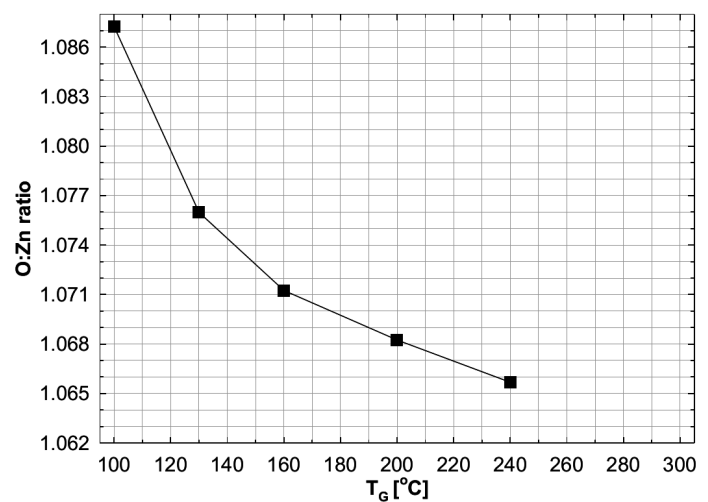

Fig. 3. O:Zn ratio curve obtained by the RBS method.

The growth temperature strongly influences the electrical properties of $\mathrm{ZnO}$ layers [5]. Therefore, Table includes not only a list of the samples with their growth temperature together with the O:Zn ratio and their thickness, as found from the RBS study, but also the results of the Hall measurements. The latter results show that for the layers grown in the temperature range of $100-300^{\circ} \mathrm{C}$ the carrier concentration changes by two orders of magnitude. The origin of the correlation between the sample stoichiometry and room temperature electron concentration is not clear. Some of our recent investigations (see e.g. [16]) indicate that zinc interstitials are the dominant shallow donor in the $\mathrm{ZnO}$ layers grown by ALD at low temperature. One of the possibilities, in line with the data shown in Table, is that $\mathrm{OH}$ groups are common in oxygen rich layers, which may contribute to the electrical properties of $\mathrm{ZnO}$ layers [17]. Oxygen interstitial is considered to be a deep donor in $\mathrm{ZnO}$ [18].

Stoichiometry measurements by X-ray photoelectron spectroscopy (XPS) were also performed [19]. These investigations show the presence of $\mathrm{N}, \mathrm{C}$, and hydrogen in the $\mathrm{ZnO}$ films. All of these elements can form compounds with oxygen (e.g. $\mathrm{OH}, \mathrm{CO}, \mathrm{CO}_{2}, \mathrm{NO}, \mathrm{NO}_{2}$, etc.). Thus we expect that the SIMNRA simulations of the RBS spectra result in an overestimated oxygen content in our films. Therefore, the absolute values of the O:Zn ratio are slightly different from those in the RBS and XPS investigations. However, in both cases the experiments indicate that the layers are oxygen rich and that the oxygen content decreases with the temperature.

The RBS analysis does not take into account the content of light elements like hydrogen, carbon or nitrogen. The $\mathrm{H}$ analysis is impossible by this method, but $\mathrm{C}$ or $\mathrm{N}$ signals should be visible in the RBS spectra, which is not the case, as shown in Fig. 1. Simulations of the RBS experimental spectra with the data provided by the XPS (C and N contents) were performed, but were not consistent with the experimental results. This is likely to be due to different depth regions examined by these two methods. XPS examines only the near surface layer, whereas RBS can reach much deeper regions. Thus, we cannot exclude the $\mathrm{C}$ and $\mathrm{N}$ presence at a very low level if these elements are located mostly in the close surface region of the examined layers.

\subsection{The quality of crystalline $\mathrm{ZnO}$ films}

$\mathrm{ZnO}$ layers deposited on $\mathrm{Si}$ do not reveal an overall crystalline arrangement in the RBS measurements and the main crystalline axis was not found in any of the channelling experiments. $\mathrm{ZnO}$ films deposited on Si substrate are polycrystalline, as can be seen in Fig. 4a,b showing the SEM image of the $\mathrm{ZnO}$ layers grown by ALD at 100 and $300^{\circ} \mathrm{C}$. The layer deposited at $100^{\circ} \mathrm{C}$ has small rice-like grains, whereas the layer deposited at $300{ }^{\circ} \mathrm{C}$ much larger and irregular grains. On the contrary, the layers deposited on the $\mathrm{GaN}$ /sapphire templates at $300{ }^{\circ} \mathrm{C}$ reveal crystalline structure. Channeling spectra were collected for two ALD layers grown on the GaN/sapphire template and for two commercial bulk crystalline samples (MaTecK ${ }^{\mathrm{TM}}$ and Semiconductor Wafer Inc. SWI). Figure 5a shows a couple of random and aligned spectra for the ALD layer (S722 sample) grown thicker than the polycrystalline $\mathrm{ZnO} / \mathrm{Si}$ films. For higher than $500 \mathrm{~nm}$ layer thickness the $\mathrm{ZnO} / \mathrm{GaN}$ interface can be hardly seen. Figure $5 \mathrm{~b}$ shows the aligned spectra for all 4 samples. The $\chi_{\min }$ parameter measured just behind the surface peak is $3.0 \%$ and $3.4 \%$ for the ALD layers. For commercial bulk samples (MaTecK and SWI) this value is $2.5 \%$ and $4.5 \%$, respectively. Thus we conclude that the crystalline quality of ALD layers grown at $300^{\circ} \mathrm{C}$ on the $\mathrm{GaN} /$ sapphire templates is very good. 


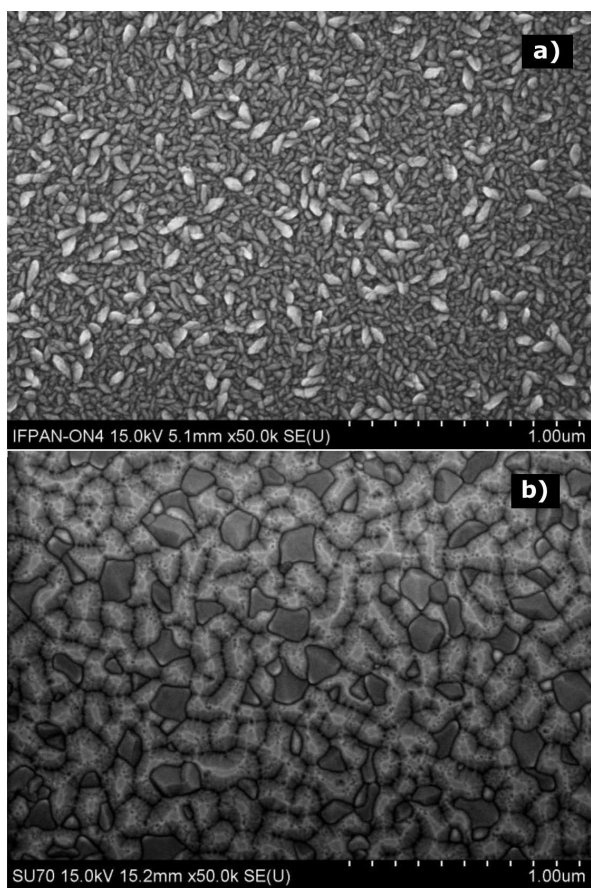

Fig. 4. SEM image of the $\mathrm{ZnO}$ layers deposited on $\mathrm{Si}$ at (a) $100{ }^{\circ} \mathrm{C}$, (b) $300{ }^{\circ} \mathrm{C}$.

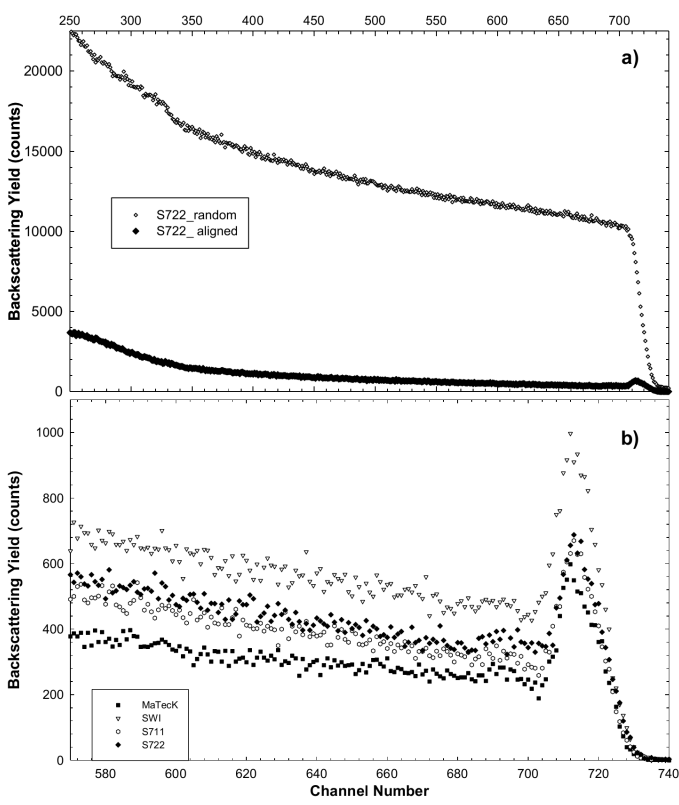

Fig. 5. (a) RBS random and aligned spectra for the $\mathrm{ZnO}$ layer deposited on $\mathrm{GaN}$ at $300{ }^{\circ} \mathrm{C}$ measured with 1.7 MeV He ions, (b) the RBS aligned spectra obtained for the $\mathrm{ZnO}$ layers deposited on GaN by ALD and two commercial $\mathrm{ZnO}$ bulk crystals.

\section{Conclusions}

Polycrystalline $\mathrm{ZnO}$ films and epitaxial $\mathrm{ZnO}$ layers were grown at low temperature by ALD. RBS/channeling measurements were carried out. The composition and thickness of the layers were determined. The layers are oxygen rich. Clear dependence of the oxygen content on the growth temperature was revealed. At higher growth temperatures a lower oxygen content was found. We observed also a correlation between growth temperature, oxygen content and conductivity, but no clear explanation is proposed.

The RBS/channelling investigations indicate a highly crystalline quality of the $\mathrm{ZnO}$ layers grown by the ALD on $\mathrm{GaN} / \mathrm{Al}_{2} \mathrm{O}_{3}$ templates at $300^{\circ} \mathrm{C}$.

\section{Acknowledgments}

The research was partially supported by the European Community within the European Regional Development Fund, through the grant Innovative Economy (POIG.01.01.02-00-008/08), and also as an Integrating Activity "Support of Public and Industrial Research Using Ion Beam Technology (SPIRIT)" under EC contract no. 227012

\section{References}

[1] M. Godlewski, E. Guziewicz, T. Krajewski, P. Kruszewski, Ł. Wachnicki, K. Kopalko, A. Wójcik, V. Osinniy, Microelectron. Eng. 85, 2434 (2008).

[2] S. Gieraltowska, L. Wachnicki, B.S. Witkowski, T.A. Krajewski, M. Godlewski, E. Guziewicz, Thin Solid Films 520, 4694 (2012).

[3] M. Godlewski, E. Guziewicz, G. Łuka, T. Krajewski, M. Łukasiewicz, Ł. Wachnicki, A. Wachnicka, K. Kopalko, A. Sarem, B. Dalati, Thin Solid Films 518, 1145 (2009).

[4] G. Luka, L. Wachnicki, B.S. Witkowski, T.A. Krajewski, R. Jakiela, E. Guziewicz, M. Godlewski, Mater. Sci. Eng. B 176, 237 (2011).

[5] U. Ozgur, D. Hofstetter, H. Morkoç, Proc. IEEE 98 1255 (2010).

[6] E. Guziewicz, M. Godlewski, T. Krajewski, Ł. Wachnicki, A. Szczepanik, K. Kopalko, A. WójcikGłodowska, E. Przeździecka, W. Paszkowicz, E. Łusakowska, P. Kruszewski, N. Huby, G. Tallarida, S. Ferrari, J. Appl. Phys. 105, 122413 (2009).

[7] M. Ritala, M. Leskela, in: Handbook of Thin Films Materials, Ed. H.S. Nalwa, Academic Press, San Diego 2001, Ch. 2, p. 103.

[8] E. Katsia, N. Huby, G. Tallarida, B. KutrzebaKotowska, M. Perego, S. Ferrari, F.C. Krebs, E. Guziewicz, M. Godlewski, V. Osinniy, G. Łuka, Appl. Phys. Lett. 94, 143501 (2009).

[9] P.Y. Stakhira, G.L. Pakhomov, V.V. Cherpak, D. Volynyuk, G. Luka, M. Godlewski, E. Guziewicz, Z.Yu. Hotra, Cent. Eur. J. Phys. 8, 798 (2010).

[10] U. Ozgur, Ya.I. Alivov, C. Liu, A. Teke, M.A. Reshchikov, S. Dogan, V. Avrutin, S.J. Cho, H. Morkoç, J. Appl. Phys. 98, 041301 (2005).

[11] W.K. Chu, J.W. Mayer, M.A. Nicolet, Backscattering Spectrometry, Academic Press, California 1978.

[12] A.V. Kuchuk, M. Guziewicz, R. Ratajczak, M. Wzorek, V.P. Kladko, A. Piotrowska, Mater. Sci. Forum 645-648, 737 (2010). 
[13] A. Turos, J. Gaca, M. Wojcik, L. Nowicki, R. Ratajczak, R. Groetzschel, F. Eichhorn, N. Schell, Nucl. Instrum. Methods Phys. Res. B 219-220, 618 (2004).

[14] R. Ratajczak, J. Gaca, M. Wójcik, A. Stonert, K. Pagowska, J. Borysiuk, A. Turos, Vacuum 83, S148 (2009).

[15] M. Mayer, SIMNRA User's Guide, Max PlanckInstitute-fur-Plasmaphysik, Garching, Germany 1997, Report IPP 9/113.

[16] G. Luka, P. Stakhira, V. Cherpak, D. Volynyuk, Z. Hotra, M. Godlewski, E. Guziewicz, B. Witkowski, W. Paszkowicz, A. Kostruba, J. Appl. Phys. 108, 064518 (2010).

[17] N. Huby, S. Ferrari, E. Guziewicz, M. Godlewski, V. Osinniy, Appl. Phys. Lett. 92, 023502 (2008).
[18] T.A. Krajewski, G. Luka, S. Gieraltowska, A.J. Zakrzewski, P.S. Smertenko, P. Kruszewski, L. Wachnicki, B.S. Witkowski, E. Lusakowska, R. Jakiela, M. Godlewski, E. Guziewicz, Appl. Phys. Lett. 98, 263502 (2011).

[19] E. Guziewicz, M. Godlewski, L. Wachnicki, T.A. Krajewski, G. Luka, S. Gieraltowska, R. Jakiela, A. Stonert, W. Lisowski, M. Krawczyk, J.W. Sobczak, A. Jablonski, Semicond. Sci. Technol. 27, 074011 (2012). 